\title{
IS902, an insertion element of the chronic-enteritis-causing Mycobacterium avium subsp. silvaticum
}

\author{
Michael T. Moss, ${ }^{*}$ Zahida P. Malik, Mark L. V. Tizard, Elizabeth P. Green, \\ JEREMY D. SANDERSON and JOHN HERMON-TAYLOR
}

Department of Surgery, St George's Hospital Medical School, Tooting, London SW17 ORE, UK

(Received 27 June 1991; revised 2 September 1991; accepted 18 September 1991)

\begin{abstract}
An insertion sequence element of Mycobacterium avium subsp. silvaticum was isolated and its complete nucleotide squence determined. IS902 is 1470 bp in size and is repeated 10-12 times per genome. An open reading frame of 1200 bp was identified, encoding a protein product of $M_{\mathrm{r}}$ 43932. This protein is highly similar to the predicted proteins of IS900 of Mycobacterium paratuberculosis, IS116 of Streptomyces clavuligerus and IS110 of Streptomyces coelicolor. IS 902 lacks terminal inverted repeats and flanking direct repeats but displays insertion site specificity.
\end{abstract}

\section{Introduction}

IS 900 , identified in a Crohn's disease isolate of Mycobacterium paratuberculosis, was the first mycobacterial insertion sequence (IS) element to be reported and characterized (Green et al., 1989). IS900 showed homology to the previously identified IS110 of Streptomyces coelicolor (Bruton \& Chater, 1987) and more recently to IS116 of Streptomyces clavuligerus (Leskiw et al., 1990). Together, these elements appear to constitute a family of related IS elements and are distinct from the IS elements and IS-like repetitive DNA sequences identified in Mycobacterium tuberculosis (Eisenach et al., 1988; Hermans et al., 1990; Thierry et al., 1990), Mycobacterium leprae (Clark-Curtiss \& Docherty, 1989) and Mycobacterium fortuitum (Martin et al., 1990).

When used as a probe, IS 900 identified restriction fragment length polymorphisms (RFLPs) able to distinguish between mycobacterial species (McFadden et al., $1987 b$; Hampson et al., 1989). On the basis of their respective RFLP patterns, $M$. paratuberculosis and the closely related Mycobacterium avium could be differentiated with considerable ease. When hybridized with IS 900 , a woodpigeon strain of $M$. avium [recently designated $M$. avium subsp. silvaticum by Thorel et al. (1990)] produced a unique multi-banded RFLP pattern

Abbreviation: RFLP, restriction fragment length polymorphism.

The nucleotide sequence data reported in this paper have been submitted to EMBL and have been assigned the accession number X58030.
(McFadden et al., 1988), suggesting the presence of an IS900-related IS element within the genome of this organism.

Mycobacterium paratuberculosis causes chronic enteritis in cattle and other animals (Chiodini et al., $1984 a$ ) and growing evidence points to the involvement of this organism in Crohn's disease in humans (Chiodini et al., 1984b, c; McFadden et al., $1987 a$; Sanderson et al., 1991). M. avium subsp. silvaticum can also cause chronic enteritis in animals (Matthews \& McDiarmid, 1979) and preliminary work (M. T. Moss, unpublished results) suggests that this organism may also be involved in Crohn's disease.

In this paper we report that IS902, the IS900-related element from $M$. avium subsp. silvaticum, has the characteristic features of the previously proposed family of unique IS elements (Green et al., 1989; Leskiw et al., 1990). Target sites for IS902 insertion have been identified and their comparison with the insertion sites of IS900 and IS 116 revealed conserved motifs. The amino acid sequences encoded by these elements were similarly observed to show a high degree of homology.

\section{Methods}

Mycobacterial isolates. Table 1 lists the isolates examined in this study, together with details of their respective sources.

Preparation of mycobacterial DNA. Mycobacterial cells were grown in Dubos medium containing $2 \mu \mathrm{g}$ mycobactin $\mathrm{J} \mathrm{ml}^{-1}$ (Rhône-Mérieux) for 3-4 weeks at $37^{\circ} \mathrm{C}$. Cells were harvested by centrifugation at 5000 r.p.m. for $15 \mathrm{~min}$, then lysed according to the method described 
Table 1. Isolates of Mycobacterium avium subsp. silvaticum used in this study

\begin{tabular}{clc}
\hline \hline Isolate & $\begin{array}{c}\text { Animal } \\
\text { source }\end{array}$ & $\begin{array}{c}\text { RFLP } \\
\text { type }\end{array}$ \\
\hline $0016^{*}$ & Deer & 1 \\
$0109^{*}$ & Goat & 2 \\
$0011^{*}$ & Woodpigeon & 2 \\
$0013^{*}$ & Woodpigeon & 2 \\
$0009 \dagger$ & Woodpigeon & 3 \\
$0010 \dagger$ & Woodpigeon & 3 \\
$0012 \dagger$ & Woodpigeon & 3 \\
$0015 \dagger$ & Woodpigeon & 3 \\
$0020 \dagger$ & Woodpigeon & 3 \\
$0108 \dagger$ & Woodpigeon & 3 \\
\hline \hline
\end{tabular}

- F. Portaels, Institute of Tropical Medicine, Antwerp, Belgium. † M. F. Thorel, Centre National d'Etudes Vétérinaires et Alimentaires, LCRV, Maisons Alfort Cedex, France.

‡ This study.

by Visuvanathan et al. (1989). Following two phenol/chloroform extractions, genomic DNA was recovered by ethanol precipitation.

Genomic library production. $M$. avium subsp. silvaticum genomic DNA (isolate 0016) was digested for $1 \mathrm{~h}$ at $37^{\circ} \mathrm{C}$ with 1 unit of BamHI per $\mu \mathrm{g}$ of total DNA. DNA fragments were fractionated by electrophoresis on a $1 \%(w / v)$ agarose gel. The $1-5 \mathrm{~kb}$ fragments were isolated from the gel using a GeneClean kit as described by the supplier (Bio 101), then ligated into the BamHI site of pUC18. Recombinant plasmids were cloned into the Escherichia coli DH5 (Gibco BRL) using standard techniques.

DNA probes and genomic library screening. A $1.5 \mathrm{~kb}$ NruI fragment of pMB22 (Green et al., 1989) containing the entire IS 900 element was labelled with $\left[\alpha-{ }^{32}\right.$ P]dCTP (ICN Biomedicals) by the random hexanucleotide priming technique of Feinberg \& Vogelstein (1984). Colony lifts and Southern blots (Southern, 1975) were hybridized with this radiolabelled probe. Hybridizations were carried out at $65^{\circ} \mathrm{C}$ overnight, as described previously (Moss et al., 1991). Membranes were washed at $65^{\circ} \mathrm{C}$ in $3 \times \mathrm{SSC}, 0.1 \% \mathrm{SDS}$ for $2 \times 30 \mathrm{~min}$, prior to autoradiography ( $1 \times \mathrm{SSC}$ is $0.15 \mathrm{M}-\mathrm{NaCl}, 0.015 \mathrm{M}$-trisodium citrate, pH 7.0).

Sequencing strategy. Two clones, pZM22 and pZM25, were subjected to double-stranded DNA sequencing by the chain-terminating method (Sanger et al., 1977) using Sequenase (USB), and 10\% (v/v) DMSO. In each sequencing reaction, $10 \mathrm{ng}$ of primer was used with $1 \mu \mathrm{g}$ of linearized plasmid DNA. The reaction mixes were electrophoresed through $6 \%$ and $8 \%(w / v)$ acrylamide gels, in the presence or absence of $40 \%(v / v)$ formamide. Sequencing data were initiated from sequencing primers $F$ and $R$, which flank the multi-cloning region of pUC18. Primer F (5'-AACAGCTATGACCATG) is equivalent to the M13 reverse primer and primer $R\left(5^{\prime}-\right.$ GTAAAACGACGGCCAGT) is the M13 'universal' primer. New sequencing primers were selected from the newly determined sequences, chemically synthesized (Oswel DNA Services) and used to extend the DNA sequences in the direction $5^{\prime}$ to 3'. Using this strategy, overlapping sequences were generated, extending along both strands of the two clones.

Computer analysis of nucleotide and predicted amino acid sequences. Sequence data were assembled and analysed on a PC AT using StadenPlus software (Amersham). Codon usage analysis (Staden \& McLachlan, 1982) and comparison with IS900 was used to determine the open reading frame (ORF) within IS902. The CLUSTAL program (Higgins \&
Sharp, 1988) [running via SEQNET at SERC Daresbury] was employed for the comparison and alignment of the nucleotide sequence and predicted protein sequence of IS 902 with the ORFs of IS $900(M$. paratuberculosis), IS 116 (Streptomyces clavuligerus) and IS110 (Streptomyces coelicolor A3(2)).

\section{Results}

Southern blots of BamHI-digested $M$. avium subsp. silvaticum isolates (Table 1) were hybridized with radiolabelled IS900 (see Methods). Multiple banding patterns were observed (data not shown), confirming the existence of multiple copies of an IS900-related insertion sequence (IS) element within the genome of the $M$. avium subsp. silvaticum isolates. This element has been designated IS902. The multiple banding patterns differentiated the 10 isolates into three RFLP types. One isolate exhibited the RFLP type 1 pattern, three isolates exhibited the RFLP type 2 pattern and six isolates the RFLP type 3 pattern (Table 1). Fig. $1(a)$ shows one example of each of the three RFLP type patterns. The varying intensities of the hybridizing bands are due to the presence of doublets and/or bands carrying more than one copy of the element.

A genomic library was constructed with DNA from isolate 0016. Colony lifts of about 4000 recombinant clones were screened with radiolabelled IS 900 (see Methods) and two clones, pZM22 and pZM25, hybridizing strongly with this probe were recovered. Characterization by restriction mapping and Southern blotting (data not shown) confirmed that the two clones were unique isolates, each containing a complete copy of IS902. The restriction site profile of pZM22 is shown in Fig. 2. The restriction site profiles of both clones only differed within the genomic DNA flanking their respective copies of IS 902 .

The $2.3 \mathrm{~kb}$ insert of clone pZM 22 and the $2.5 \mathrm{~kb}$ insert of clone pZM 25 produced identical multiple banding patterns when used to probe Southern blots of the $10 M$. avium subsp. silvaticum isolates (data not shown). The three RFLP patterns identified with these two copies of IS902 were virtually identical (a solitary band did not hybridize) to the patterns obtained when the isolates were probed with radiolabelled IS900 (Fig. 1a). The missing band (identified by arrowheads in Fig. 1a) may represent a single copy of a second IS element present in the genome of these isolates which shows more homology to IS900 than to IS902. This element was identified in all $10 M$. avium subsp. silvaticum isolates (data not shown). Fig. $1(b)$ records the results of probing the Southern blot shown in Fig. $1(a)$ with the radiolabelled insert of clone pZM22. With IS902 containing no internal BamHI sites the hybridization results suggest the presence of 10-12 copies of the IS902 element within the $M$. avium subsp. 


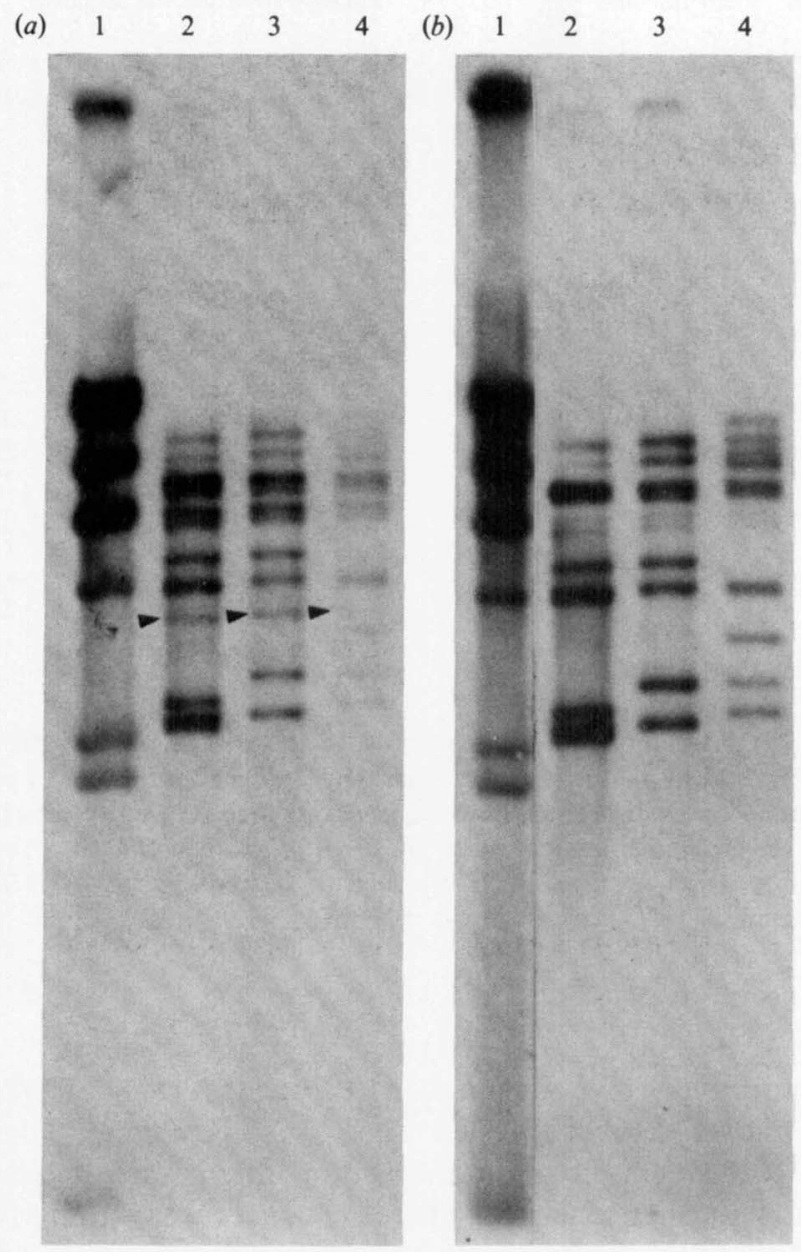

Fig. 1. Southern blots of BamHI-digested M. avium subsp. silvaticum isolates. One isolate was chosen to represent each of the three RFLP patterns identified. (a) The three isolates hybridized with radiolabelled IS $900 ;(b)$ the blot was reprobed with the radiolabelled $2.3 \mathrm{~kb} \mathrm{BamHI}$ insert of pZM22. Lanes: 1, HindIII digest of $\lambda$ DNA; 2, isolate 0016 (RFLP type 1); 3, isolate 0013 (RFLP type 2); 4, isolate 0009 (RFLP type 3$)$. The arrowheads in (a) indicate a second IS 900 -related IS element. silvaticum genome. IS900 is repeated 15-20 times in the $M$. paratuberculosis genome.

Clones pZM22 and pZM25 were each sequenced in both directions and in a similar manner. Fig. 2 outlines the strategy used to sequence IS 902 in clone pZM22. The complete nucleotide sequence of IS902 is shown in Fig. 3. The element is $1470 \mathrm{bp}$ in length, with an overall $\mathrm{G}+\mathrm{C}$ content of $62 \mathrm{~mol} \%$, the same as the $\mathrm{G}+\mathrm{C}$ composition of the host genomic DNA which flanks the element. Homologies were observed with IS 900 of M.paratuberculosis (Green et al., 1989), IS116 of S. clavuligerus (Leskiw et al., 1990) and IS 110 of $S$. coelicolor (Bruton \& Chater, 1987). DIAGON plots comparing these sequences identified the $3^{\prime}$ end as the region showing the greatest homology between the four IS elements (data not shown). Weak homology was also observed with IS1000 from Thermus thermophilus (Ashby \& Bergquist, 1990). Comparison (1) of the sequence of the two copies of IS 902 for their points of divergence and (2) with the endpoints and putative insertion site sequence of IS 900 allowed identification of the $5^{\prime}$ and $3^{\prime}$ termini of IS 902 .

Analysis of the sequences adjacent to the $5^{\prime}$ and $3^{\prime}$ termini revealed that, in common with IS 900 and IS 116 , IS 902 contained neither flanking direct repeats nor terminal inverted repeats. However, analysis of the sequences flanking IS 902 in clones pZM22 and pZM25 identified sequences $\left(\mathrm{CATN}_{8} \mathrm{CCTTC}\right.$ and CATN ${ }_{7}$ CCTTC, respectively) similar to the putative insertion site sequences described for IS900 and IS 116 . Fig. 4(a) shows the putative insertion site sequences for two copies of IS902, five copies of IS900 and a single copy of IS116. Regions conserved between these eight sequences are marked. A consensus insertion site sequence for this family of related IS elements is shown in Fig. $4(b)$.

Leskiw et al. (1990) drew attention to the sequences CAT and CCT, occurring to the left and right

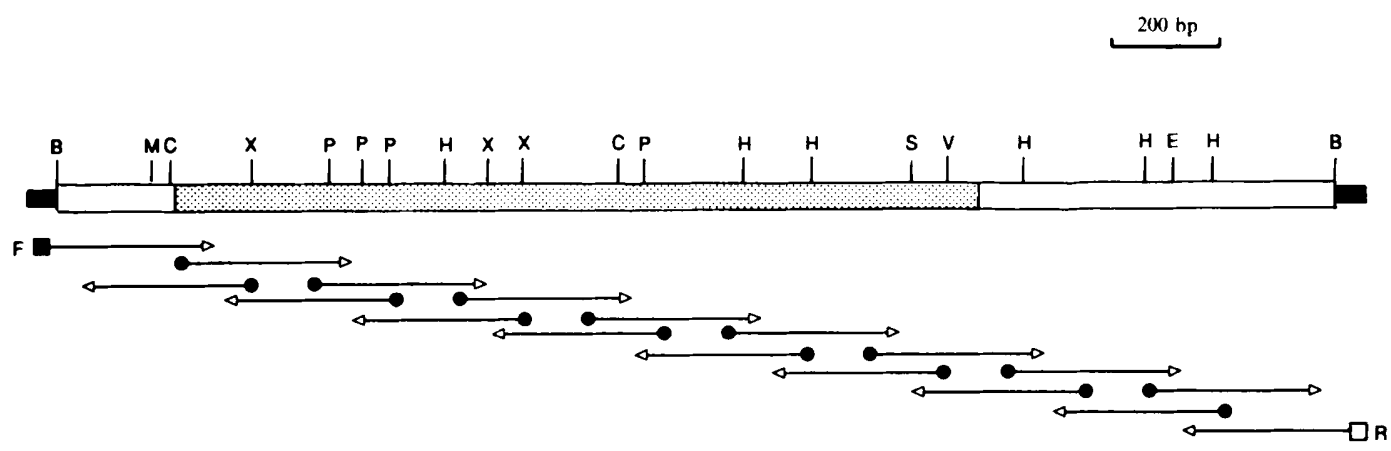

Fig. 2. The restriction map and strategy used to sequence IS 902 in pZM22. IS 902 (圆) and flanking genomic DNA ( $\square$ ) were sequenced using a series of overlapping primers $(\bullet \rightarrow)$. Sequence data were initiated from primers $F\left(\square \rightarrow ; 5^{\prime}-\right.$ GTAAAACGACGGCCAGT $)$ and

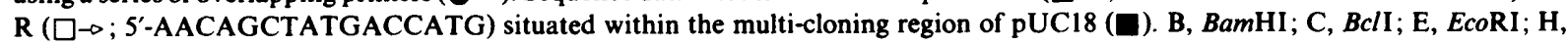
HinfI; M, SmaI; P, PvuI ; S, SalI; V, PvuII; X XhoII. 


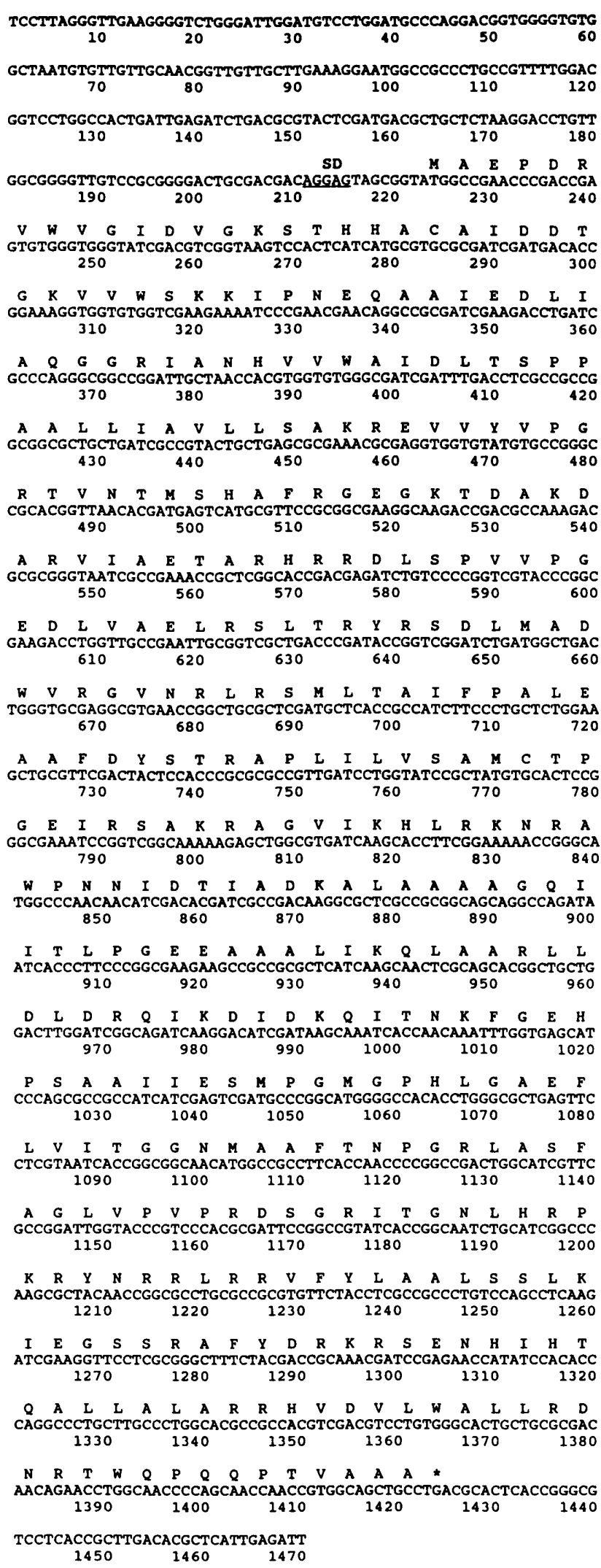

Fig. 3. Nucleotide sequence of IS 902 and inferred amino acid sequence of ORF1200. A potential Shine-Dalgano (SD) sequence, preceding the predicted initiation codon (ATG), is underlined. *, Stop codon. (a) Element/clone

Putative insertion site sequence

IS $902 / \mathrm{pZM} 22^{(1)}$

IS $902 / \mathrm{pZM} 25^{(1)}$

IS $900 / \mathrm{pMB} 22^{(2)}$

IS $900 / \mathrm{pMB} 15^{(2)}$

IS $900 / \mathrm{pMB}^{(2)}$

IS $900 / \mathrm{pMBJ}^{(3)}$

${\text { IS } 900 / \mathrm{pMBJ}^{(3)}}^{(3)}$

IS $116 / \mathrm{pIJ} 702^{(4)}$

CATGATCAATT'CCTTTC

CATTTACAGT'CCTTTC

CATGTGGTGT'CTCCTTC

CATGTGTT'CCCCTTA

CATGGTGG'CCCCTTG

CATGACGÁCTCCTTG

CATGTGǴCTCCTTC

CATGGTCGG'TCTCCTGGT

(b) Consensus:

$\operatorname{CAT}(\mathrm{N})_{6-9} \mathrm{CCT}$

Fig. 4. (a) Comparison of the putative insertion sequences of IS902, IS 900 and IS 116 . (b) Consensus insertion sequence for this family of related IS elements. Underlined sequences are conserved between each of the eight insertion sequences. $\boldsymbol{\nabla}$, Insertion position of each of the respective IS elements. (1), This study; (2), Green et al. (1989); (3), unpublished data; (4), Leskiw et al. (1990).

respectively of both junctions of the IS 116 and IS 900 elements, and suggested their involvement in the alignment of a circular transposition intermediate and its insertion site sequence. These sequences were similarly found at the $5^{\prime}$ and $3^{\prime}$ element-insertion site junctions of IS902. Our analysis of two copies of IS902, five copies of IS 900 and a single copy of IS 116 revealed that the spacing between these two sequences is invariably 5-9 nucleotides for the $5^{\prime} \mathrm{CAT} / \mathrm{CCT}$ pairing and 7-9 nucleotides for the $3^{\prime} \mathrm{CAT} / \mathrm{CCT}$ pairing (Fig. 5a). Consensus sequences for the $5^{\prime}$ and $3^{\prime}$ element-insertion site junctions of this family of related IS elements are shown in Fig. 5(b).

An ORF of 1200 nucleotides was identified within the $1470 \mathrm{bp}$ of IS 902 . Occurring between positions 225 and 1418 , ORF 1200 encodes a protein of 400 amino acids $\left(M_{\mathrm{r}}\right.$ 43932). When the amino acid sequence of ORF 1200 was aligned with those of the ORFs of IS900, IS 116 and IS 110 using the CLUSTAL program, values were obtained for the degree of homology existing at the amino acid level between the protein products of these four elements. IS 902 showed $50 \%$ identity with both IS 900 and IS 116 and $35 \%$ identity with IS 110 (data not shown). DIAGON plots comparing the amino acid sequence of ORF 1200 of IS 902 with the ORFs of IS 900 , IS 116 and IS 110 were prepared (Fig. 6). The highly conserved regions existing between the protein products of these four IS elements are identified as a broken diagonal. 


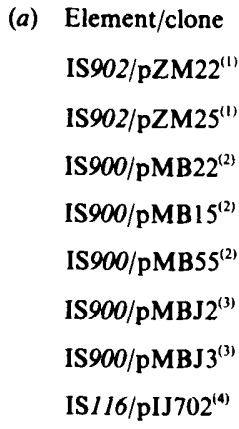

(b) Consensus:
5 ' element-insertion site junction $3^{\prime}$ element-insertion site junction
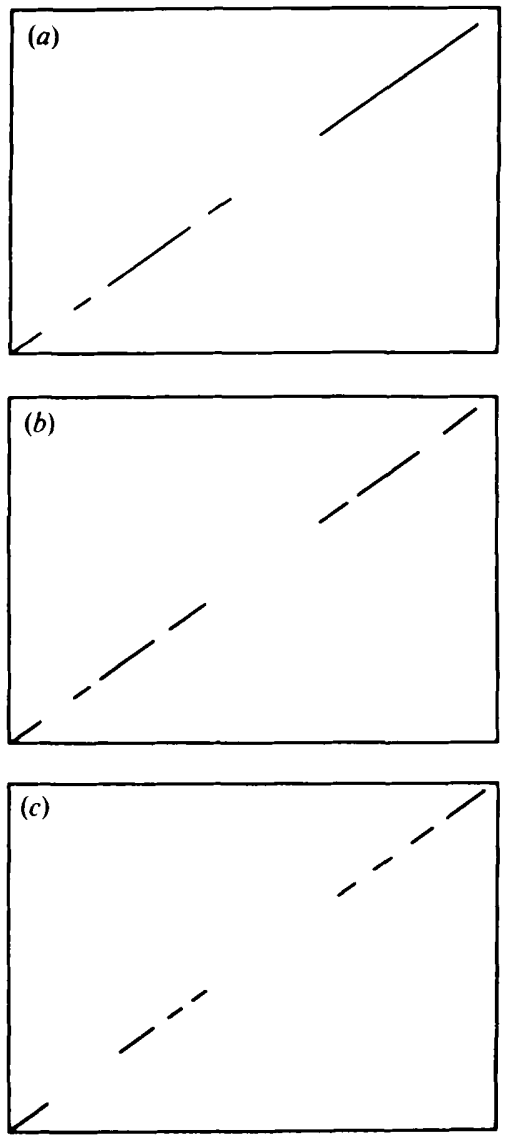

Fig. 6. DIAGON comparison of the predicted protein of ORF1200 of IS 902 (vertical) with (a), the predicted protein of ORF1197 of IS900 (horizontal); (b), the predicted protein of ORF1197 of IS116 (horizontal); (c), the predicted protein of ORF1215 of IS 110 (horizontal). DIAGON plots were prepared by proportional matching using the Dayhoff MDM78 matrix. Span length 11 amino acids.

\section{Discussion}

A previously uncharacterized insertion element has been identified and isolated from the genome of a deer isolate of $\boldsymbol{M}$. avium subsp. silvaticum. This element has been designated IS 902 . Analysis of Southern blots hybridized with IS902-derived probes suggests that there are 10-12 copies of the element dispersed throughout the genome. The presence of different numbers of copies of IS902 in these isolates raises the possibility that this element is mobile. In 10 independent disease isolates of $M$. avium subsp. silvaticum examined to date, three RFLP patterns have been identified. IS902 will be as useful in the precise identification of strains of $\boldsymbol{M}$. avium subsp. silvaticum as IS 900 has proven to be in the identification of $M$. paratuberculosis strains (Collins et al., 1990; Whipple et al., 1990).

The element is $1470 \mathrm{bp}$ in length with an ORF of 1200 nucleotides, coding for a protein of 400 amino acids $\left(M_{\mathrm{r}}\right.$ 43932). The ORF of IS 902 and its predicted protein product are virtually identical in length and size to those of IS900 (Green et al., 1989), IS116 (Leskiw et al., 1990) and IS 110 (Bruton \& Chater, 1987).

The overall homology at the nucleotide level between IS902, IS900, IS 116 and IS 110 is low. Greatest homology exists between these four elements in their $3^{\prime}$ regions. IS902 shows no homology with the recently identified IS6110, an IS3-like element from $M$. tuberculosis (Thierry et al., 1990) and IS6100, an IS6-like element from $M$. fortuitum (Martin et al., 1990). Weak homology was observed with IS 1000 from Thermus thermophilus (Ashby \& Bergquist, 1990). 
CLUSTAL analysis and DIAGON plots revealed significant homology between the amino acid sequence of the protein product of IS 902 and those of IS 900 , IS 116 and IS 110 . The degree of conservation existing between the predicted protein products of these four elements presumably reflects important structural domains and is highly suggestive that these proteins will exhibit comparable functions. The homologies found with IS900, IS 116 and IS 110 support the proposal that IS 902 belongs to the family of IS elements identified by ourselves (Green $e t$ al., 1989) and by Leskiw et al. (1990). No significant homology was observed between IS 902 and the putative mycobacterial transposase of IS6100 or the putative mycobacterial integrase of Tn610 (Martin et al., 1990).

An insertion site sequence sharing sequence homology with the previously described target sites of IS900 and IS 116 was identified for IS902 insertion into the $M$. avium subsp. silvaticum genome. Although each of these IS elements has its own unique target site sequence, the sequences CAT and CCT are constant features of each of them. The spacing between the CAT and CCT sequences is most probably an important feature of the target sites. Examination of eight insertion site sequences for IS902, IS 900 and IS 116 (Fig. 4) revealed that the CAT and CCT sequences were invariably separated by 6-9 nucleotides. It was also observed that insertion of the appropriate IS element resulted in positioning an internal CCT sequence within 5-9 nucleotides of the insertion site CAT and positioning an internal CAT within 7-9 nucleotides of the insertion site CCT sequence (Fig. 5). Successful insertion of the appropriate element would appear to recreate CAT/CCT sequence spacing comparable to the original insertion site. Analysis of the nucleotide sequences adjacent to the IS902 termini revealed an absence of flanking direct repeats and terminal inverted repeats, features characteristic of most IS elements previously characterized. In this respect, IS 902 again resembles both IS900 and IS 116 , which also lack these features.

$M$. paratuberculosis and $M$. avium subsp. silvaticum cause chronic enteritis (Johne's disease) in animals (Chiodini et al., 1984a; Matthews \& McDiarmid, 1979) and evidence is gathering for their involvement in human Crohn's disease (Chiodini et al., 1984b, c; McFadden et al., 1987a; Sanderson et al., 1991). On the basis of the IS 902 nucleotide sequence, we are currently developing PCR for the specific and sensitive detection of $M$. avium subsp. silvaticum to complement the previously described PCR for the detection of $M$. paratuberculosis (Moss et al., 1991). Together these PCR assays will prove useful for the detection of these enteritis-associated mycobacteria both in the veterinary field and in human Crohn's disease.
Note added in proof. Since submitting this manuscript we have discovered that an insertion sequence from Mycobacterium avium has been independently characterized by Kunze et al. (1991), Molecular Microbiology 5, 2265-2272. This shows $98 \%$ DNA homology to IS902 and has been designated IS 901 .

This work was supported by grants from the Wellcome Trust, Action Research and the Ileostomy Association of Great Britain and Ireland to whom we would like to express our appreciation. We also thank $F$. Portaels and M. F. Thorel for the provision of isolates.

\section{References}

Ashry, M. K. \& Bergquist, P. L. (1990). Cloning and sequence of IS1000, a putative insertion sequence from Thermus thermophilus HB 8. Plasmid 24, 1-11.

Bruton, C. J. \& Chater, K. F. (1987). Nucleotide sequence of IS110, an insertion sequence of Streptomyces coelicolor A3(2). Nucleic Acids Research 15, 7053-7065.

Chiodini, R. J., Van Kruiningen, H. J. \& Merkal, R. S. (1984a). Ruminant paratuberculosis (Johne's disease): the current status and future prospects. Cornell Veterinarian 74, 218-262.

Chiodini, R. J., Van Kruiningen, H. J., Thayer, W. R., Merkal, R. S. \& Couteau, J. A. (1984b). Possible role of mycobacteria in inflammatory bowel disease. I. An unclassified Mycobacterium species isolated from patients with Crohn's disease. Digestive Diseases and Sciences 29, 1073-1079.

Chiodini, R. J., Van Kruiningen, H. J., Thayer, W. R., Merkal, R. S. \& Couteau, J. A. (1984c). Characteristics of an unclassified Mycobacterium species isolated from patients with Crohn's disease. Journal of Clinical Microbiology 20, 966-971.

Clark-Curtiss, J. E. \& Docherty, M. A. (1989). A species-specific repetitive sequence in Mycobacterium leprae DNA. Journal of Infectious Diseases 159, 7-15.

Collins, D. M., Gabric, D. M. \& DE Lisle, G. W. (1990). Identification of two groups of Mycobacterium paratuberculosis strains by restriction endonuclease analysis and DNA hybridization. Journal of Clinical Microbiology 28, 1591-1596.

EisenaCh, K. D., Crawford, J. T. \& Bates, J. H. (1988). Repetitive DNA sequences as probes for Mycobacterium tuberculosis. Journal of Clinical Microbiology 26, 2240-2245.

FeinberG, A. P. \& Vogelstein, B. (1984). A technique for radiolabelling DNA restriction fragments to high specific activity. Analytical Biochemistry 137, 226-227.

Green, E. P., Tizard, M. L. V., Moss, M. T., Thompson, J., Winterbourne, D. J., McFadden, J. J. \& Hermon-Taylor, J. (1989). Sequence and characteristics of IS900, an insertion element identified in a human Crohn's disease isolate of Mycobacterium paratuberculosis. Nucleic Acids Research 17, 9063-9073.

hampson, S. J., Portaels, F., Thompson, J., Green, E. P., Moss, M. T., HERMON-TAYLOR, J. \& MCFADDEN, J. J. (1989). DNA probes demonstrate a single highly conserved strain of Mycobacterium avium infecting AIDS patients. Lancet i, 65-68.

Hermans, P. W. M., Van Soolingen, D., Dale, J. W., Schuitema, A. R. J., McAdam, R. A., Catty, D. \& Van Embden, J. D. A. (1990). Insertion element IS986 from Mycobacterium tuberculosis: a useful tool for diagnosis and epidemiology of tuberculosis. Journal of Clinical Microbiology 28, 2051-2058.

Higgins, D. G. \& Sharp, P. M. (1988). Clustal: a package for performing multiple sequence alignment on a microcomputer. Gene 73, 237-244.

Leskiw, B. K., Mevarech, M., Barritt, L. S., Jensen, S. E., Henderson, D. J., Hopwood, D. A., Bruton, C. J. \& Chater, K. F. (1990). Discovery of an insertion sequence, IS116, from Streptomyces clavuligerus and its relatedness to other transposable 
elements from actinomycetes. Journal of General Microbiology 136, 1251-1258.

Martin, C., Timm, J., Rauzier, J., Gomez-Lus, R., Davies, J. \& GICQUEL, B. (1990). Transposition of an antibiotic resistance element in mycobacteria. Nature, London 345, 739-743.

Matthews, P. R. J. \& McDiarmid, A. (1979). The production in bovine calves of a disease resembling paratuberculosis with a Mycobacterium sp. isolated from a woodpigeon (Columba palumbus L). Veterinary Record 104, 286.

MCFADDEN, J. J., BUTCheR, P. D., ChIOdINI, R. \& HeRmon-TAYLOR, J. (1987a). Crohn's disease-isolated mycobacteria are identical to Mycobacterium paratuberculosis, as determined by DNA probes that distinguish between mycobacterial species. Journal of Clinical Microbiology 25, 796-801.

McFadden, J. J., Butcher, P. D., Thompson, J., Chiodini, R. \& HERMON-TAYLOR, J. (1987b). The use of DNA probes identifying restriction-fragment-length polymorphisms to examine the $M y c o-$ bacterium avium complex. Molecular Microbiology 1, 283-291.

McFadden, J. J., Thompson, J., Hull, E., Hampson, S., Stanford, J. \& HeRMON-TAYLOR, J. (1988). The use of cloned DNA probes to examine organisms isolated from Crohn's disease tissue. In Inflammatory Bowel Disease : Current Status and Future Approach, pp. 515-520. Edited by R. P. MacDermott. Amsterdam: Elsevier.

Moss, M. T., Green, E. P., Tizard, M. L., Malik, Z. P. \& HermonTAYLOR, J. (1991). Specific detection of Mycobacterium paratuberculosis by hybridisation with a fragment of the insertion element IS900. Gut 32, 395-398.

Sanderson, J. D., Malik, Z., Moss, M. T., Tizard, M. V., Green, E. P. \& Hermon-Taylor, J. (1991). Polymerase chain reaction (PCR) directly reports Mycobacterium paratuberculosis genomes in Crohn's disease tissue DNA extracts. Gastroenterology 100, A247.
SANGer, F., Nicklen, S. \& Coulson, A. R. (1977). DNA sequencing with chain-terminating inhibitors. Proceedings of the National Academy of Sciences of the United States of America 74, 5463-5467.

SOUTHERN, E. M. (1975). Detection of specific sequences among DNA fragments separated by gel electrophoresis. Journal of Molecular Biology 98, 503-517.

Staden, R. \& McLaChlan, A. D. (1982). Codon preference and its use in identifying protein coding regions in long DNA sequences. Nucleic Acids Research 10, 141-156.

Thierry, D., Cave, M. D., Eisenach, K. D., Crawford, J. T., Bates, J. H., GicQuel, B. \& GuesDon, J. L. (1990). IS6110, an IS-like element of Mycobacterium tuberculosis complex. Nucleic Acids Research 18, 188.

Thorel, M. F., KRichevsky, M. \& Lévy-Frébault, V. V. (1990). Numerical taxonomy of mycobactin-dependent mycobacteria, emended description of Mycobacterium avium, and description of Mycobacterium avium subsp. avium subsp. nov., Mycobacterium avium subsp. paratuberculosis subsp. nov., and Mycobacterium avium subsp. silvaticum subsp. nov. International Journal of Systematic Bacteriology 40, 254-260.

Visuvanathan, S., Moss, M. T., Stanford, J. L., Hermon-Taylor, J. \& MCFADDEN, J. J. (1989). Simple enzymic method for isolation of DNA from diverse bacteria. Journal of Microbiological Methods 10. 59-64.

WhipPle, D., KAPKe, P. \& VARY, C. (1990). Identification of restriction fragment length polymorphisms in DNA from $M y c o b a c$ terium paratuberculosis. Journal of Clinical Microbiology 28, 25612564. 